\title{
Synthesis of metal-fluoride nanoparticles supported on thermally reduced graphite oxide
}

\author{
Alexa Schmitz ${ }^{1}$, Kai Schütte ${ }^{1}$, Vesko llievski ${ }^{1}$, Juri Barthel ${ }^{2}$, Laura Burk ${ }^{3}$, Rolf Mülhaupt ${ }^{3}$, \\ Junpei Yue ${ }^{4}$, Bernd Smarsly ${ }^{4}$ and Christoph Janiak ${ }^{*} 1, \S$
}

\section{Full Research Paper}

Address:

${ }^{1}$ Institut für Anorganische Chemie und Strukturchemie,

Heinrich-Heine-Universität Düsseldorf, 40204 Düsseldorf, Germany,

${ }^{2}$ Gemeinschaftslabor für Elektronenmikroskopie RWTH-Aachen,

Ernst Ruska-Centrum für Mikroskopie und Spektroskopie mit

Elektronen, D-52425 Jülich, Germany, ${ }^{3}$ Freiburg Materials Research

Center and Institute for Macromolecular Chemistry,

Albert-Ludwigs-University Freiburg, 79104 Freiburg, Germany and

${ }^{4}$ Physikalisch-Chemisches Institut, Justus-Liebig-Universität Gießen,

35392 Gießen, Germany

Email:

Christoph Janiak ${ }^{*}$-janiak@uni-duesseldorf.de

* Corresponding author

§ Fax: +49-211-81-12287; Tel: +49-211-81-12286

Keywords:

ionic liquids; material synthesis; metal-fluoride nanoparticles;

microwave irradiation; thermally reduced graphite oxide
Beilstein J. Nanotechnol. 2017, 8, 2474-2483.

doi:10.3762/bjnano.8.247

Received: 08 August 2017

Accepted: 20 October 2017

Published: 22 November 2017

Associate Editor: A. Gölzhäuser

(C) 2017 Schmitz et al.; licensee Beilstein-Institut. License and terms: see end of document.

\footnotetext{
Abstract

Metal-fluoride nanoparticles, $\left(\mathrm{MF}_{x}-\mathrm{NPs}\right)$ with $\mathrm{M}=\mathrm{Fe}, \mathrm{Co}, \mathrm{Pr}, \mathrm{Eu}$, supported on different types of thermally reduced graphite oxide (TRGO) were obtained by microwave-assisted thermal decomposition of transition-metal amidinates, $\left(\mathrm{M}\left\{\mathrm{MeC}[\mathrm{N}(\mathrm{iPr})]_{2}\right\}_{n}\right)$ or $\left[\mathrm{M}(\mathrm{AMD})_{n}\right]$ with $\mathrm{M}=\mathrm{Fe}(\mathrm{II}), \mathrm{Co}(\mathrm{II}), \operatorname{Pr}(\mathrm{III})$, and tris(2,2,6,6-tetramethyl-3,5-heptanedionato)europium, Eu(dpm) 3 , in the presence of TRGO in the ionic liquid (IL) 1-butyl-3-methylimidazolium tetrafluoroborate ([BMIm] $\left.\left[\mathrm{BF}_{4}\right]\right)$. The crystalline phases of the

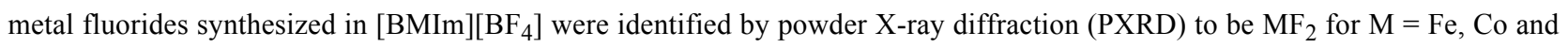
$\mathrm{MF}_{3}$ for $\mathrm{M}=\mathrm{Eu}$, Pr. The diameters and size distributions of $\mathrm{MF}_{x} @$ TRGO were from (6 \pm 2$)$ to (102 \pm 41$)$ nm. Energy-dispersive $\mathrm{X}$-ray spectroscopy (EDX) and X-ray photoelectron spectroscopy (XPS) were used for further characterization of the MF $\mathrm{N}_{x} \mathrm{NPs}_{\text {. }}$ Electrochemical investigations of the $\mathrm{FeF}_{2}-\mathrm{NPs} @ \mathrm{TRGO}$ as cathode material for lithium-ion batteries were evaluated by galvanostatic charge/discharge profiles. The results indicate that the $\mathrm{FeF}_{2}-\mathrm{NPs} @ \mathrm{TRGO}$ as cathode material can present a specific capacity of $500 \mathrm{mAh} / \mathrm{g}$ at a current density of $50 \mathrm{~mA} / \mathrm{g}$, including a significant interfacial charge storage contribution. The obtained nanomaterials show a good rate capacity as well $(220 \mathrm{mAh} / \mathrm{g}$ and $130 \mathrm{mAh} / \mathrm{g})$ at a current density of $200 \mathrm{and} 500 \mathrm{~mA} / \mathrm{g}$, respectively.
} 


\section{Introduction}

Graphene is the parent compound of all graphitic carbon forms and a form of nanocarbon [1]. It has a large specific surface, is electrically and thermally conductive and has a high mechanical resistance [2]. The International Union of Pure and Applied Chemistry (IUPAC) defines graphene as an isolated two-dimensional monolayer of $\mathrm{sp}^{2}$-hybridized carbon atoms [3], extended in a honeycomb-type structure that consist of six-membered rings [3]. Functionalized graphene is obtained from graphite by graphite oxidation followed by thermal reduction. During the thermal reduction of graphite oxide by flash pyrolysis, the decomposition of epoxy, carbonyl and carboxyl groups accounts for a build-up of pressure that exfoliates functionalized graphene [4].

In 1958, Hummers and Offeman reported on a "graphene" synthesis by oxidation of graphite with sodium nitrate, potassium permanganate and sulfuric acid followed by thermal reduction through rapid heating under nitrogen to $300-1000{ }^{\circ} \mathrm{C}$ [5], yielding thermally reduced graphite oxide (TRGO) as a graphene-type material (Scheme S1, Supporting Information File 1) [6]. The thermal reduction results in the loss of most of the oxygen functionalities on the surface. This can be controlled by varying the reduction temperature, yielding different types of TRGO characterized by decreasing oxygen functionality with increasing temperature [7]. Due to its remaining oxygen functionalities and its porosity TRGO is an attractive carrier material for the immobilization of very small nanoparticles [8-12].

In 2009, the first nanoparticles@TRGO were synthesized by heating graphite oxide with $\mathrm{Pt}, \mathrm{Ru}$ or Pd complexes under a nitrogen atmosphere [13]. Alternatively, salts of palladium and other metals are readily immobilized on graphene oxide by means of cation exchange with carboxylic acid groups, followed by thermal reduction to produce metal nanoparticles supported on functionalized graphene. Such palladium nanoparticles supported on graphene were used as highly active catalysts for the Suzuki-Miyaura coupling reaction [14]. In 2011, metal carbonyls in dispersion with TRGO and ionic liquid (IL) were exposed to short low-energy microwave irradiation. The resulting Ru@TRGO and Rh@TRGO particles had high catalytic hydrogenation activity [12]. Metallic nanoparticles on graphene have important technical applications [15-22]. They can be used as composite materials [23,24], in chemical sensors [25], electrodes for fuel cells [26-28], for catalysis [29-32] or for hydrogen storage [33].

Because of their high ionic charge, polarity and dielectric constant, ILs are an ideal media for microwave reactions and for the stabilization of M-NPs [34-37]. Soft wet-chemical synthe- sis in organic solvents from metal-organic complexes is an essential method to obtain metal or metal alloy nanoparticles [38-50].

The synthesis of inorganic nanomaterials is thoroughly investigated but still requires well-established, simple protocols with inexpensive and non-toxic chemicals for many of the important inorganic nanoparticles [51,52]. Metal-fluoride nanoparticles, $\mathrm{MF}_{x}$-NPs are important in materials science and modern chemistry $[53,54]$. Nanoscale main-group metal fluorides can be obtained from a fluorolytic sol-gel route by the reaction of the metal alkoxide or acetate with anhydrous HF in a suitable organic solvent. Strong Lewis-acidic main-group metal fluorides such as $\mathrm{AlF}_{3}$ or $\mathrm{MgF}_{2}$ represent a new class of heterogeneous nanocatalysts $[55,56]$. Transition-metal-fluoride nanoparticles are applied, for example, as cathode materials in lithiumion batteries for vehicles and other mobile devices [57]. In this field, the modification of lithium-transition-metal electrodes is a very important issue to improve the performance of lithiumion batteries [58-61].

Herein, we report on the utilization of metal amidinates $\left(\mathrm{M}\left\{\mathrm{MeC}[\mathrm{N}(\mathrm{iPr})]_{2}\right\}_{n}\right.$ or $\left.\mathrm{M}(\mathrm{AMD})_{n}\right)$ of iron, cobalt and praseodymium and of tris(2,2,6,6-tetramethyl-3,5-heptanedionato)europium, $\mathrm{Eu}(\mathrm{dpm})_{3}$ as precursors with different types of TRGO for the synthesis of nanocomposite materials in ionic liquids (ILs) to yield selectively phase-pure metal-fluoride nanoparticles ( $\mathrm{MF}_{x}$-NPs) supported on the TRGO as stable colloids (Scheme 1). The used TRGO starting materials differed in the temperatures at which they were reduced $(300,400$ or $750{ }^{\circ} \mathrm{C}$ ) and in the presence of sulfur functionalities.

\section{Results and Discussion}

Transition-metal amidinates $\left[\mathrm{M}(\mathrm{AMD})_{n} ; \mathrm{M}=\mathrm{Fe}(\mathrm{II}), \mathrm{Co}(\mathrm{II})\right.$, $\operatorname{Pr}(\mathrm{III})]$ as well as $\mathrm{Eu}(\mathrm{dpm})_{3}$ were dissolved or suspended under nitrogen atmosphere in the dried and deoxygenated ionic liquid together with the selected type of thermally reduced graphene oxide (TRGO). Complete decomposition by microwave irradiation of the precursors in IL was achieved after only $10 \mathrm{~min}$ for $\mathrm{Co}(\mathrm{II})$ and $15 \mathrm{~min}$ for $\mathrm{Fe}(\mathrm{II}), \mathrm{Eu}(\mathrm{III})$ and $\mathrm{Pr}(\mathrm{III})$ using a low power of $50 \mathrm{~W}$ to give a temperature of $220^{\circ} \mathrm{C}$ in the reaction mixture (Scheme 1). Black dispersions of nanocomposite materials were reproducibly obtained by repeated decompositions of the precursors/TRGO.

Different types of TRGO were employed for the deposition of the metal-fluoride nanoparticles. The number value of the suffix at TRGO specifies the temperature (in degree Celsius) that was used to reduce the graphite oxide to TRGO (Scheme S1 and Scheme S2 in Supporting Information File 1). Thiol-functionali- 


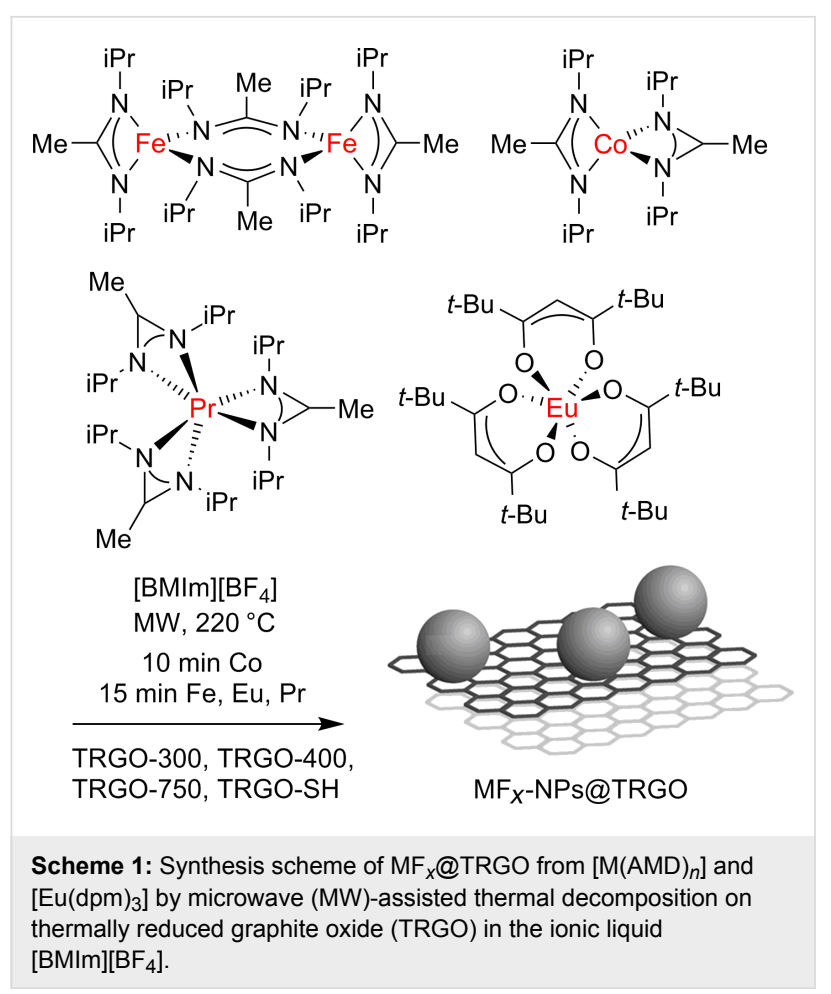

zed TRGO-SH [62] was additionally used to support metalfluoride nanoparticles.

The morphology, crystalline phase $\left(\mathrm{MF}_{x}-\mathrm{NPs}\right)$, size and size dispersion of the nanoparticles was analyzed by powder X-ray diffraction (PXRD) and transmission electron microscopy (TEM). X-ray photo electron spectroscopy (XPS) was used to determine the metal/fluoride ratio, as well as the metal oxidation state. The crystalline phase analysis was based on positively matching the experimental powder X-ray diffractograms (PXRDs) to metal-fluoride structures deposited in the crystallographic open database (COD) (Figures S4-S19, Supporting Information File 1). For example, for $\mathrm{PrF}_{3}$ the PXRD matches the hexagonal close-packed (hcp) structure of praseodymium metal trifluoride with space group $\mathrm{P}_{3} / \mathrm{mcm}$ (Figure 1).

The formation of metal fluorides instead of metal nanoparticles in the IL $[\mathrm{BMIm}]\left[\mathrm{BF}_{4}\right]$ must be rationalized from the fluoride content of the IL tetrafluoroborate anion. It is known that the $\left[\mathrm{BF}_{4}\right]^{-}$anion hydrolyzes or decomposes to fluoride, $\mathrm{F}^{-}$, in the presence of small amounts of residual water in the IL, which is very difficult to remove from hydrophilic $[\mathrm{BMIm}]\left[\mathrm{BF}_{4}\right][63]$ Water is used in IL synthesis during the washing process following the anion exchange from typically chloride to tetrafluoroborate. Anion analyses by ion chromatography of the purified ILs yielded fluoride contents of 0.1 to $0.4 \mathrm{wt} \%$ for [BMIm] $\left[\mathrm{BF}_{4}\right]$ ILs [64]. Heating the ILs for the amidinate decomposition may lead to further hydrolysis of $\left[\mathrm{BF}_{4}\right]^{-}$and fluo-

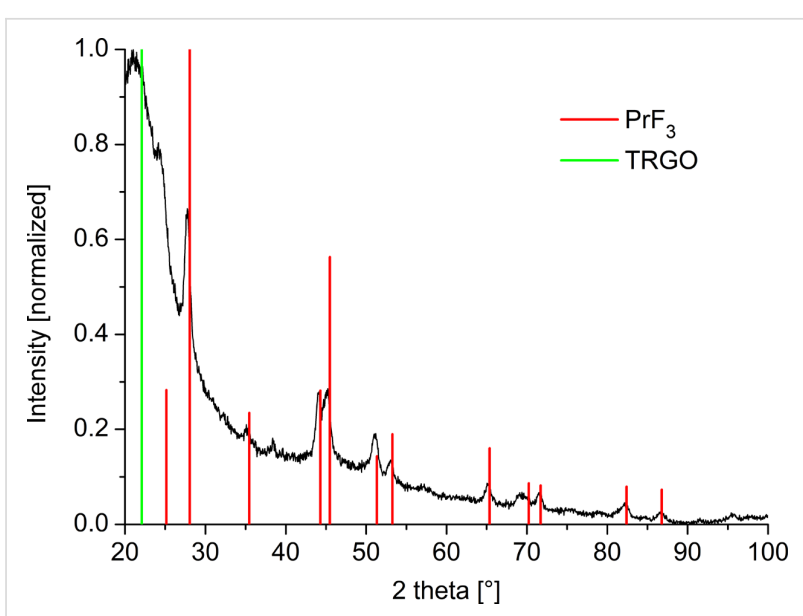

Figure 1: Example PXRD of 0.5 wt \% $\mathrm{PrF}_{3} @ T R G O-S H$ in $[\mathrm{BMIm}]\left[\mathrm{BF}_{4}\right]$ synthesized from $\left[\mathrm{Pr}(\mathrm{AMD})_{3}\right]$. $\mathrm{PrF}_{3}$ reference reflections in red from COD 1010984. For the diffractogram with indexed reflections see Figure S18 in Supporting Information File 1. The PXRDs for the other samples are given in Figures S4-S19 in Supporting Information File 1.

ride formation with the residual water. Fluoride ions can then lead to the formation of metal fluorides [65]. Alternatively, reactive metal atoms or metal clusters may also abstract fluoride from $\left[\mathrm{BF}_{4}\right]^{-}$anions.

ILs are already recognized as solvents and as reactants. In the synthesis of nanoparticles of the fluoridosilicates $\mathrm{A}_{2} \mathrm{SiF}_{6}$ $(\mathrm{A}=\mathrm{Li}, \mathrm{Na}, \mathrm{K}, \mathrm{Rb}, \mathrm{Cs})$ the IL $[\mathrm{BMIm}]\left[\mathrm{PF}_{6}\right]$ was used both as solvent and fluoride source in an ionothermally assisted microwave synthesis [66]. Decomposition of transition-metal amidinates in $[\mathrm{BMIm}]\left[\mathrm{BF}_{4}\right]$ yielded metal fluoride nanoparticles for $\mathrm{Mn}, \mathrm{Fe}$ and $\mathrm{Co}$ [63]. The reaction of metal acetate (hydrate) precursors in ethylene glycol and an excess of [BMIm] $\left[\mathrm{BF}_{4}\right]$ gave fluoride nanoparticles [67]. Mesoporous carbon/iron carbide hybrids were synthesized using mesoporous silica as template and the ionic liquid $[\mathrm{BMIm}]\left[\mathrm{FeCl}_{4}\right]$ as carbon and iron source [68]. $\mathrm{CuCl}$ nanoplatelets were obtained from mixtures of a $\mathrm{Cu}$-containing ionic liquid crystal and 6-O-palmitoyl ascorbic acid [69].

Analysis of the $\mathrm{MF}_{x} @$ TRGO nanocomposite materials by (high-resolution) transmission electron microscopy ((HR-)TEM) (Figure 1, Figures S4-S19 in Supporting Information File 1) indicated the formation of $\mathrm{MF}_{x}$ nanoparticles with typical diameters between 4 and $30 \mathrm{~nm}$ supported on the TRGO. The sizes and size dispersions of the metal-fluoride nanoparticles are summarized in Table 1 . The diameters of the $\mathrm{MF}_{x}$ nanoparticles were derived from evaluation of as many reflections as possible in the powder X-ray diffractograms by using the Scherrer equation. Further, sizes and size dispersion were obtained from measuring at least 50 particles in the TEM images (Figure 2 and Supporting Information File 1). High- 


\begin{tabular}{|c|c|c|c|c|}
\hline precursor & $\begin{array}{l}\text { identified phase of } \\
\mathrm{MF}_{X}-\mathrm{NPs}^{\mathrm{b}} \text { on TRGO }\end{array}$ & $\begin{array}{l}\text { NP diameter from } \\
\text { PXRD [nm] }{ }^{\mathrm{c}}\end{array}$ & $\begin{array}{l}\text { particle diameter from } \\
\text { TEM }[n m]^{d, e}\end{array}$ & $\begin{array}{l}\text { particle diameter without } \\
\text { TRGO from TEM [nm] }\end{array}$ \\
\hline \multicolumn{5}{|c|}{ TRGO-300 } \\
\hline $\mathrm{Fe}(\mathrm{AMD})_{2}$ & $\mathrm{FeF}_{2}$ & $8-30$ & $\begin{array}{c}26 \pm 7 \\
102 \pm 41^{f}\end{array}$ & $65 \pm 18^{g}$ \\
\hline $\mathrm{Co}(\mathrm{AMD})_{2}$ & $-^{\mathrm{h}}$ & $16-31$ & ${ }^{\mathrm{h}}$ & $43 \pm 11^{g}$ \\
\hline $\operatorname{Pr}(\mathrm{AMD})_{3}$ & $\mathrm{PrF}_{3}$ & $9-17$ & $15 \pm 4$ & $11 \pm 6^{g}$ \\
\hline $\mathrm{Eu}(\mathrm{dpm})_{3}$ & $\mathrm{EuF}_{3}$ & $15-21$ & $14 \pm 6$ & $21 \pm 7^{i}$ \\
\hline \multicolumn{5}{|c|}{ TRGO-400 } \\
\hline $\mathrm{Fe}(\mathrm{AMD})_{2}$ & $\mathrm{FeF}_{2}$ & $9-20$ & $30 \pm 10$ & $65 \pm 18^{g}$ \\
\hline $\mathrm{Co}(\mathrm{AMD})_{2}$ & $-{ }^{h}$ & $16-31$ & $-^{\mathrm{h}}$ & $43 \pm 119$ \\
\hline $\operatorname{Pr}(\mathrm{AMD})_{3}$ & $\mathrm{PrF}_{3}$ & $10-14$ & $10 \pm 3$ & $11 \pm 6^{g}$ \\
\hline $\mathrm{Eu}(\mathrm{dpm})_{3}$ & $\mathrm{EuF}_{3}$ & $13-21$ & $14 \pm 4$ & $21 \pm 7^{i}$ \\
\hline \multicolumn{5}{|c|}{ TRGO-750 } \\
\hline $\mathrm{Fe}(\mathrm{AMD})_{2}$ & $\mathrm{FeF}_{2}$ & $10-26$ & $6 \pm 2$ & $65 \pm 18^{g}$ \\
\hline $\mathrm{Co}(\mathrm{AMD})_{2}$ & $-^{\mathrm{h}}$ & $21-38$ & $-^{\mathrm{h}}$ & $43 \pm 11^{g}$ \\
\hline $\operatorname{Pr}(\mathrm{AMD})_{3}$ & $\mathrm{PrF}_{3}$ & $8-16$ & $17 \pm 4$ & $11 \pm 6^{g}$ \\
\hline $\mathrm{Eu}(\mathrm{dpm})_{3}$ & $\mathrm{EuF}_{3}$ & $14-22$ & $18 \pm 4$ & $21 \pm 7^{i}$ \\
\hline \multicolumn{5}{|c|}{ TRGO-SH } \\
\hline $\mathrm{Fe}(\mathrm{AMD})_{2}$ & $\mathrm{FeF}_{2}$ & $16-28$ & $6 \pm 2$ & $65 \pm 18 \mathrm{~g}$ \\
\hline $\mathrm{Co}(\mathrm{AMD})_{2}$ & $\mathrm{CoF}_{2}$ & $-j$ & $9 \pm 2$ & $43 \pm 11 \mathrm{~g}$ \\
\hline $\operatorname{Pr}(\mathrm{AMD})_{3}$ & $\mathrm{PrF}_{3}$ & $14-21$ & $6 \pm 2$ & $11 \pm 6^{g}$ \\
\hline $\mathrm{Eu}(\mathrm{dpm})_{3}$ & $\mathrm{EuF}_{3}$ & $13-23$ & $15 \pm 5$ & $21 \pm 7^{i}$ \\
\hline
\end{tabular}

a 0.5 wt \% MF $-\mathrm{NP} /[\mathrm{BMIm}]\left[\mathrm{BF}_{4}\right]$ dispersions obtained by microwave-assisted heating for 10 min for Co, 15 min for Fe, Pr and Eu precursors; bthe

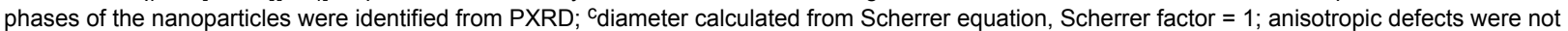
considered; a range is given for diameter values derived from different reflections; ${ }^{d}$ average diameter and standard deviation $\sigma$; ${ }^{2}$ see Experimental section for TEM measurement conditions; at least 50 particles were used for the analysis; ${ }^{f}$ width and length of the rods; ${ }^{\text {data }}$ from [63]; ${ }^{h}$ no separated nanoparticles; 'data from [76]; 'jno reflections in PXRD.
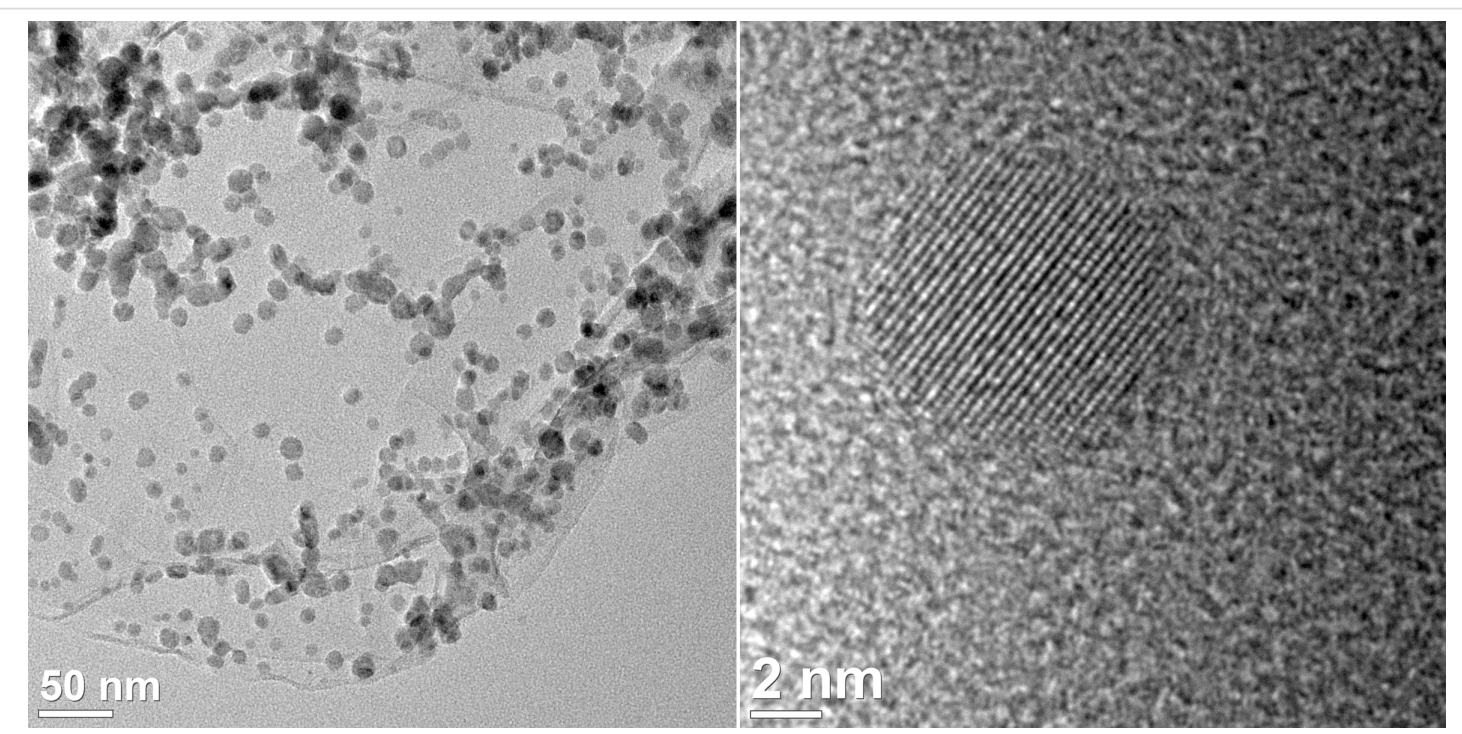

Figure 2: TEM images of $\operatorname{PrF}_{3} @ T R G O-400$ dispersions from $\left[\operatorname{Pr}(\mathrm{AMD})_{3}\right]$ in $[\mathrm{BMIm}]\left[\mathrm{BF}_{4}\right]$. 
resolution TEM images frequently showed interference patterns (lattice planes), which is an indication of crystallinity. For the iron difluoride nanoparticles nanorods were obtained besides nanoparticles (Figures S4, S8, S12 and S16 in Supporting Information File 1). For praseodymium trifluoride, spherical crystalline nanoparticles were found with clear interference patterns within the particles (Figure 2 and Figure S6, S10, S14, S18 in Supporting Information File 1). Eu(dpm) $)_{3}$ gave crystalline facetted particles that laid partly next to the TRGO (Figures S7, S11 and S19 in Supporting Information File 1). After the reaction of cobalt amidinate on TRGO-300 to TRGO-750 rather aggregated metal assemblies were obtained under the used reaction conditions so that individual particles were difficult to discern and no clear sizes could be derived (Figures S9 and S13 in Supporting Information File 1). TRGO-SH was derived from TRGO-400 by reaction with lithium diisopropylamide (LDA) and propylene sulfide. Subsequently, the TRGO-SH carries sulfur functionalities on the surface that were intended to increase the interactions with the nanoparticles (see Scheme S2, Supporting Information File 1) [7]. Also, from cobalt amidinate individual $\mathrm{CoF}_{2}$ nanoparticles could be deposited on TRGO$\mathrm{SH}$, showing interference patterns within the particles (Figure S17, Supporting Information File 1).

From various mineral studies the substitution of $\mathrm{F}^{-}$with $\mathrm{OH}^{-}$is well known [70-75]. Hence, it is possible that the fluoride ions in the metal fluoride nanoparticles can be partially substituted by hydroxide ions from traces of residual water. At the level of analysis that is possible with the $\mathrm{MF}_{x}$ nanoparticles we cannot, however, quantify any oxygen content in the metal-fluoride nanoparticles. In comparison to earlier works on the formation of metal-fluoride nanoparticles in [BMIm] $\left[\mathrm{BF}_{4}\right]$ the $\mathrm{MF}_{x}$ particles had a different size when deposited on TRGO, however, with no clear trend concerning an increase or a decrease of size [63-76].

XPS measurements (Figure 3, Figures S6-S10 and S12-S15 in Supporting Information File 1) can be used to further support the formation of metal fluorides. The measured electron binding energies of the metals agree with those of the metals in the oxi- dation states $+2(\mathrm{Fe}, \mathrm{Co})$ or $+3(\mathrm{Pr}, \mathrm{Eu})$ and significantly higher than those of the state $\mathrm{M}^{0}$. The $\mathrm{F} 1 \mathrm{~s}$ binding energy agrees with those found for metal fluorides, which is $2-5 \mathrm{keV}$ lower than for organic fluorides (Table 2, Tables S9-S11 in Supporting Information File 1).

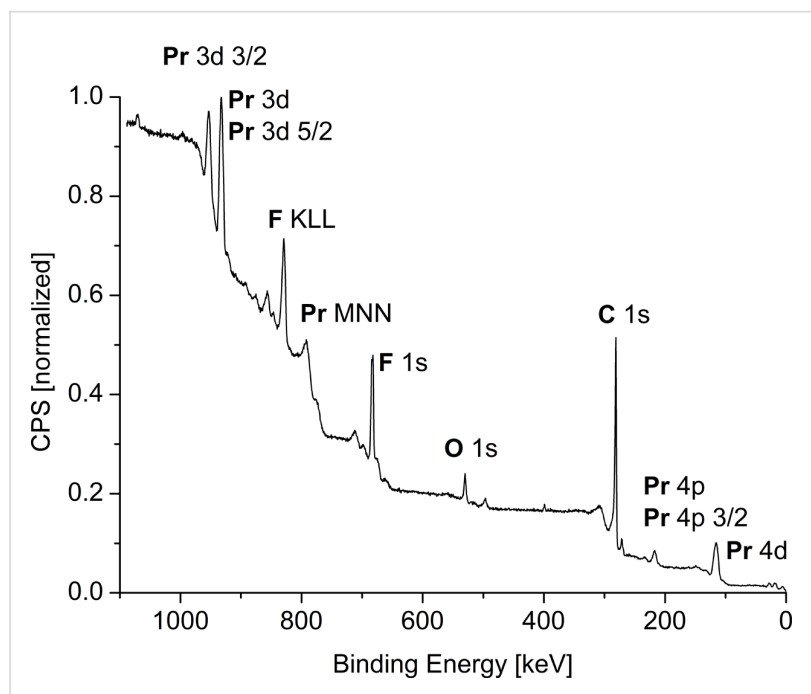

Figure 3: XPS of $\mathrm{PrF}_{3} @ T R G O-400$ dispersions from $\left[\operatorname{Pr}(\mathrm{AMD})_{3}\right]$ in [BMIm] $\left[\mathrm{BF}_{4}\right]$.

TRGO still possesses oxygen functionalities on the surface. The presence of oxygen functionalities at the graphene surface provides reactive sites for the nucleation and growth of metal nanoparticles. The nucleation and growth mechanism depends on the degree of oxygen functionalization at the graphene surface sheets, such that no nanoparticles are obtained at totally reduced graphene surfaces [7,79]. TRGO is generally regarded as a good base material for obtaining highly loaded nanoparticle-graphene hybrid materials, because of its surface functionalization [80]. A distinct possibility is the formation of hydrogen bonds between the metal-fluoride nanoparticles and the hydroxyl groups at the TRGO surface.

Batteries based on nanosized materials would yield, for example, short charging time, long lifetime and high capacity

Table 2: Comparison of XPS binding energies. ${ }^{a}$

$\mathrm{PrF}_{3} @$ TRGO-400 binding energies [keV]

\begin{tabular}{cccc}
\hline element & measured & $\operatorname{Pr}^{0}$ metal & $\operatorname{Pr}^{3+}$ oxidation state $[77,78]$ \\
$\operatorname{Pr} 3 d 5 / 2$ & 934.3 & 932 & $933-933.5$ \\
\hline F 1s & measured & metal fluorides & organic fluorides [77,78] \\
\hline
\end{tabular}

acharge calibration: C 1s $284.8 \mathrm{eV}$; comparison of XPS binding energies in other MF $_{x} @$ TRGO samples is given in Tables S9-S11 in Supporting Information File 1. 
$[81,82] . \mathrm{Li}$ et al. showed that the use of $\mathrm{FeF}_{2} \mathrm{NPs}$, instead of macroscopic $\mathrm{LiFeF}_{3}$, led to a significant improvement in the performance of the batteries [83]. The IL $[\mathrm{BMIm}]\left[\mathrm{BF}_{4}\right]$ was described as the fluoride source for the formation of $\mathrm{FeF}_{3} \mathrm{NPs}$ and their stabilization medium [84]. Iron fluorides were recognized as promising cathode materials for lithium-ion batteries due to the higher energy density compared to current cathode materials. Iron fluorides can undergo a conversion reaction delivering a theoretical capacity of $712 \mathrm{mAh} / \mathrm{g}$ for $\mathrm{FeF}_{3}$ and $571 \mathrm{mAh} / \mathrm{g}$ for $\mathrm{FeF}_{2}$ [85-87]. Here, the electrochemical performance of the obtained $\mathrm{FeF}_{2} @$ TRGO as cathode materials were evaluated by galvanostatic charge/discharge profiles as shown in Figure 4.

In the first charge/discharge profiles, there is a dip before the plateau, which is normally observed in pure $\mathrm{FeF}_{2}$ electrodes $[88,89]$. This feature corresponds to the conversion reaction of $\mathrm{FeF}_{2}$ to $\mathrm{Fe}^{0}$ and $\mathrm{LiF}$. The plateau potential is around $1.3 \mathrm{~V}$, far lower than the equilibrium potential of $2.6 \mathrm{~V}$, which can be due to the restricted process kinetics. At the following discharging curves, the plateau potential increases to $1.8 \mathrm{~V}$ due to improved process kinetics caused by the reduced particle size during the cycling $[88,89]$. The region before the plateau is corresponding to the reduction reaction from $\mathrm{Fe}^{3+}$ to $\mathrm{Fe}^{2+}$, while the part following the plateau is probably caused by the interfacial charge storage at the interface between nanosized $\mathrm{Fe}$ and the electrolyte $\mathrm{LiF}$, analogous to the phenomena in $\mathrm{RuO}_{2}$ proposed by Maier et al. [90]. The capacity is around $800 \mathrm{mAh} / \mathrm{g}$. During the charging process, there are several oxidation processes, which can be ascribed to the reaction of $\mathrm{Fe}^{0}$ to $\mathrm{Fe}^{2+}$ (at a potential lower than $3.5 \mathrm{~V}$ ) and $\mathrm{Fe}^{2+}$ to $\mathrm{Fe}^{3+}$ (at a potential higher than $3.5 \mathrm{~V}$ ) [88]. The large voltage hysteresis between discharging and charging process can be attributed to sluggish process kinetics, including, for example, phase evolution and the spatial distribution of immediate phases [88-91]. At the first discharge and charge process, the very high capacity may be caused by the formation of a solid-electrolyte interface. After several cycles at $50 \mathrm{~mA} / \mathrm{g}$, the capacity stabilizes to around $500 \mathrm{mAh} / \mathrm{g}$ and decreases to 220 and $130 \mathrm{mAh} / \mathrm{g}$ with the current density increasing to 200 and $500 \mathrm{~mA} / \mathrm{g}$, respectively. The results indicate the good rate performance of $\mathrm{FeF}_{2} @$ TRGO400 .

\section{Conclusion}

We were able to confirm the successful decomposition of transition-metal amidinates $\left[\mathrm{M}\left\{\mathrm{MeC}[\mathrm{N}(\mathrm{iPr})]_{2}\right\}_{n}\right]\left[\mathrm{M}(\mathrm{AMD})_{n}\right.$; $\mathrm{M}=\mathrm{Fe}(\mathrm{II}), \mathrm{Co}(\mathrm{II}), \operatorname{Pr}(\mathrm{III})]$ as well as tris(2,2,6,6-tetramethyl3,5-heptanedionato)europium, $\mathrm{Eu}(\mathrm{dpm})_{3}$, to metal-fluoride nanoparticles in the ionic liquid $[\mathrm{BMIm}]\left[\mathrm{BF}_{4}\right]$. We describe a simple method for the support of largely isolated metal-fluoride nanoparticles on different types of TRGO, differing in the reduction temperatures $\left(300,400\right.$ or $\left.750{ }^{\circ} \mathrm{C}\right)$ from graphite oxide and in the presence of sulfur functionalities. The nanoparticles exhibited mostly diameters of less than $30 \mathrm{~nm}$. For cobalt it was only possible to support non-aggregated $\mathrm{CoF}_{2}$ particles on TRGO-SH. The results support the advantages of the metalorganic precursor concept based on metal amidinates together with non-conventional solvents and microwave-assisted pyrolysis [92-94]. Galvanostatic charge/discharge profiles of $\mathrm{FeF}_{2} @$ TRGO-400 indicate a good rate performance of the composite material, e.g., capacities of 220 and $130 \mathrm{mAh} / \mathrm{g}$ at current densities of 200 and $500 \mathrm{~mA} / \mathrm{g}$, respectively.

\section{Experimental}

All syntheses were carried out under nitrogen or argon using Schlenk techniques, since the amidinates are hygroscopic and air sensitive. 1,3-Diisopropylcarbodiimide (>99\%), iron(II)
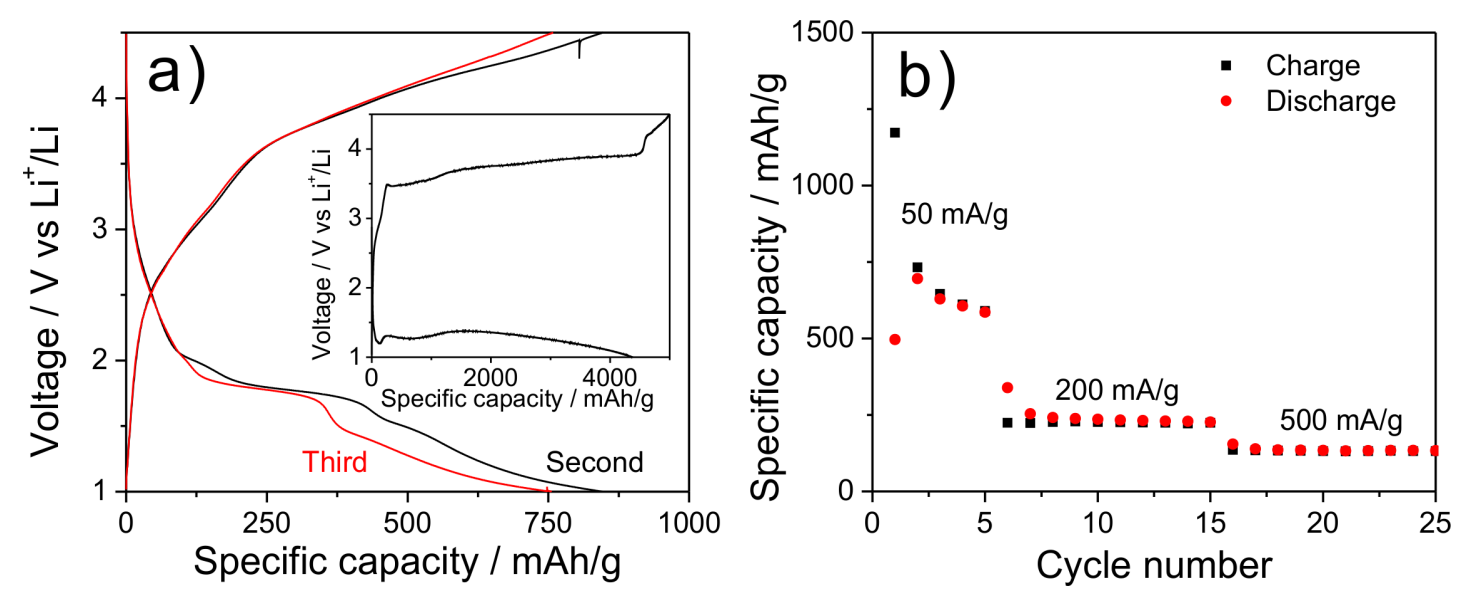

Figure 4: The electrochemical performance of $\mathrm{FeF}_{2} @ \mathrm{TRGO}-400$ as cathode material for lithium-ion batteries. (a) The galvanostatic charge/discharge profiles at a current of $50 \mathrm{~mA} / \mathrm{g}$. The inset is the profile of the first cycle. (b) The rate performance after an activation over three cycles. 
chloride (>98\%), cobalt(II) chloride (>99\%), methyllithium, 1-chlorobutane $(>99 \%)$ and 1-methylimidazole( $>99 \%)$, were purchased from Sigma-Aldrich and used without further purification. Tris(2,2,6,6-tetramethyl-3,5-heptanedionato)europium(III) ( $>99 \%$ ) was obtained from Alfa Aesar and was dried under high vacuum $\left(10^{-3} \mathrm{mbar}\right)$ for several days. Lithium amidinate was synthesized by deprotonation and methylation of 1,3-diisopropylcarbodiimide with methyllithium and subsequently reaction with metal halides according to literature procedures $[95,96]$.

The ionic liquid $[\mathrm{BMIm}]\left[\mathrm{BF}_{4}\right]$ was synthesized by reacting 1-methylimidazole with 1-chlorobutane to yield [BMIm][Cl] [BMIm] [Cl] reacted with $\mathrm{HBF}_{4}$ to give $[\mathrm{BMIm}]\left[\mathrm{BF}_{4}\right]$ [64]. Following the washing procedure with water the IL was dried under ultra-high vacuum $\left(10^{-7} \mathrm{mbar}\right)$ at $60^{\circ} \mathrm{C}$ for several days.

Thermally reduced graphene oxide (TRGO) was prepared in a two-step oxidation/thermal reduction process using natural graphite (type KFL 99.5 from AMG Mining AG, former Kropfmühl AG, Passau, Germany) as raw material. The graphite oxidation procedure of Hummers and Offeman [6] was employed. All TRGOs, differing in the reduction temperatures $\left(300,400\right.$ or $\left.750{ }^{\circ} \mathrm{C}\right)$ from graphite oxide and in the presence of sulfur functionalities, were obtained from the group of Prof. Rolf Mülhaupt, University of Freiburg. For the TRGO analyses see Supporting Information File 1 (Figures S1-S3, Tables S1-S7).

X-ray photoelectron spectroscopy, XPS-(ESCA), measurements were performed with a Fisons/VG Scientific ESCALAB $200 \mathrm{X}$ spectrometer, operating at room temperature at a pressure of $1.0 \times 10^{-8}$ bar and a sample angle of $30^{\circ}$. Spectra were recorded using polychromatic $\mathrm{Al} \mathrm{K \alpha}$ excitation $(14 \mathrm{kV}, 20 \mathrm{~mA})$ at an emission angle of $0^{\circ}$. Calibration was carried out by recording spectra with $\mathrm{Al} \mathrm{K} \alpha \mathrm{X}$-rays from clean samples of copper, silver and gold at $20 \mathrm{eV}$ and $10 \mathrm{eV}$ pass energies and comparison with reference values.

Powder X-ray diffractograms, PXRDs, were measured at ambient temperature on a Bruker D2 Phaser using a flat sample holder and $\mathrm{Cu} \mathrm{K} \alpha$ radiation $(\lambda=1.54182 \AA, 35 \mathrm{kV})$. The samples had been precipitated with acetonitrile from the NP/IL dispersion and washed several times with acetonitrile. PXRDs were measured for $1 \mathrm{~h}$. Small shifts in PXRD patterns are not uncommon for nanoparticles. A number of effects can be considered for such shifts including a range of stoichiometric composition, partly inhomogeneous element distribution, defects such as stacking and twin faults and nanosized crystalline domains being much smaller than the bulk reference ma- terial causing lattice contraction or expansion and strain [97$101]$.

The HR-TEM imaging was performed on a FEI Tecnai G2 F20 electron microscopy operated at $200 \mathrm{kV}$ accelerating voltage [102]. Digital images were recorded by a Gatan UltraScan 1000P detector. Samples were prepared using $200 \mu \mathrm{m}$ carboncoated copper grids or gold grids. The size distribution was determined manually or with the aid of the Gatan DigitalMicrograph software from at least 50 individual particles.

HR-TEM EDX spectroscopy was also performed on a FEI Tecnai G2 F20 with a high-angle energy-dispersive X-ray detector providing a resolution of $136 \mathrm{eV}$ or better for $\mathrm{Mn} \mathrm{K \alpha}$ radiation. The exposure time of individual EDX spectra was $3 \mathrm{~min}$.

Metal-fluoride nanoparticles were prepared in a nitrogen atmosphere. $10 \mathrm{mg}$ of the TRGO and the weighted amount of metalamidinate powder or $\left[\mathrm{Eu}(\mathrm{dpm})_{3}\right]$ were suspended at room temperature in the dried ionic liquid in a microwave vial in a glove box. The vial was closed with a cramp cap in the glove box before being taken out. The mass of the metal precursor was set for a $0.5 \mathrm{wt} \% \mathrm{M}-\mathrm{NP}$ dispersion in IL. The vial with the reaction mixture was placed in a microwave (CEM, Discover) and irradiated for $10 \mathrm{~min}(\mathrm{Co})$ or $15 \mathrm{~min}(\mathrm{Fe}, \mathrm{Pr}, \mathrm{Eu})$ at a power of $50 \mathrm{~W}$ to a temperature of $220^{\circ} \mathrm{C}$.

Examples of selected area electron diffraction (SAED) patterns (Figures S4 and S6 in Supporting Information File 1) have been recorded with an FEI Titan 80-300 TEM [103], operated at $300 \mathrm{kV}$ accelerating voltage. The area selection was achieved with a round aperture placed in the first intermediate image plane with a corresponding diameter of $0.64 \mu \mathrm{m}$ in the object plane. For each acquisition a sample region with a significant amount of material was placed inside the aperture. The objected was illuminated with wide-spread parallel beam obtaining focused diffraction patterns. The diffraction images were calibrated with Debye-Scherrer patterns recorded from a gold reference sample (S106, Plano GmbH, Wetzlar, Germany).

For the electrochemical measurements, the working electrodes were prepared by coating a slurry composed of $75 \mathrm{wt} \% \mathrm{FeF}_{2}-$ TRGO, $15 \mathrm{wt} \%$ active carbon and $10 \mathrm{wt} \% \mathrm{PVDF}$ in NMP on an aluminum foil. A half-cell was assembled in Ar-filled glovebox with lithium foil as counter electrode and $1 \mathrm{M} \mathrm{LiFeF}_{6}$ in ethylene carbonate/ethylmethyl carbonate (50:50) as electrolyte. The galvanostatic charge/discharge profiles were collected on a Maccor battery cycler with cut-off potentials of 4.5 and $1.0 \mathrm{~V}$ vs $\mathrm{Li}^{+} / \mathrm{Li}$. 


\section{Supporting Information}

Information about the synthesis of TRGO and TRGO-SH, the analysis of TRGO-300, $-400,-750$ and $-\mathrm{SH}$, and an overview of all samples.

\section{Supporting Information File 1}

Additional experimental data.

[http://www.beilstein-journals.org/bjnano/content/ supplementary/2190-4286-8-247-S1.pdf]

\section{Acknowledgements}

Authors are thankful to the Deutsche Forschungsgemeinschaft (DFG) for financial support in the priority project SPP 1708 through grant Ja466/31-1, followed by grant Ja466/31-2 and in the core-facilities program through grant MA 1280/40-1. The authors also gratefully acknowledge financial support of research on functionalized graphene research by the European Community as part of the EU Graphene Flagship (GAN 696656). We thank Mr. Manuel Endres for the synthesis of some of the metal amidinate precursors during his lab work for the Bachelor Thesis.

\section{ORCID ${ }^{\circledR}$ iDs}

Alexa Schmitz - https://orcid.org/0000-0002-1075-4194 Bernd Smarsly - https://orcid.org/0000-0001-8452-2663 Christoph Janiak - https://orcid.org/0000-0002-6288-9605

\section{References}

1. Rao, C. N. R.; Sood, A. K.; Subrahmanyam, K. S.; Govindaraj, A. Angew. Chem., Int. Ed. 2009, 48, 7752-7777. doi:10.1002/anie.200901678

2. Ke, Q.; Wang, J. J. Materiomics 2016, 2, 37-54. doi:10.1016/j.jmat.2016.01.001

3. Fitzer, E.; Kochling, K.-H.; Boehm, H. P.; Marsh, H. Pure Appl. Chem. 1995, 67, 473-506. doi:10.1351/pac199567030473

4. Dolbin, A. V.; Khlistyuck, M. V.; Esel'son, V. B.; Gavrilko, V. G.; Vinnikov, N. A.; Basnukaeva, R. M.; Maluenda, I.; Maser, W. K.; Benito, A. M. Appl. Surf. Sci. 2016, 361, 213-220. doi:10.1016/j.apsusc.2015.11.167

5. Appel, A.-K. Funktionalisierte Graphene aus Graphit und Kohlenstoffhybride für Polyurethan-Nanocomposite. Ph.D. Thesis, University Freiburg, Germany, 2013

6. Hummers, W. S., Jr.; Offeman, R. E. J. Am. Chem. Soc. 1958, 80, 1339. doi:10.1021/ja01539a017

7. Marquardt, D.; Beckert, F.; Pennetreau, F.; Tölle, F.; Mülhaupt, R.; Raint, O.; Hermans, S.; Barthel, J.; Janiak, C. Carbon 2014, 66, 285-294. doi:10.1016/j.carbon.2013.09.002

8. Zhou, X.; Wu, T.; Ding, K.; Hu, B.; Hou, M.; Han, B. Chem. Commun. 2010, 46, 386-388. doi:10.1039/B914763B

9. Nuvoli, D.; Valentini, L.; Alzari, V.; Scognamillo, S.; Bittolo, B. S.; Piccinini, M.; Illescas, J.; Mariani, A. J. Mater. Chem. 2011, 21 , 3428-3431. doi:10.1039/C0JM02461A
10. Zhang, B.; Ning, W.; Zhang, J.; Qiao, X.; Zhang, J.; He, J.; Liu, C.-Y. J. Mater. Chem. 2010, 20, 5401-5403. doi:10.1039/c0jm01029d

11. Wang, X.; Fulvio, P. F.; Baker, G. A.; Veith, G. M.; Unocic, R. R.; Mahurin, S. M.; Chi, M.; Dai, S. Chem. Commun. 2010, 46, 4487-4489. doi:10.1039/c0cc00799d

12. Marquardt, D.; Vollmer, C.; Thomann, R.; Steurer, P.; Mülhaupt, R.; Redel, E.; Janiak, C. Carbon 2011, 49, 1326-1332. doi:10.1016/j.carbon.2010.09.066

13. Gotoh, K.; Kawabata, K.; Fuji, E.; Morishige, K.; Kinumoto, T.; Miyazaki, Y.; Ishida, H. Carbon 2009, 47, 2120-2124. doi:10.1016/j.carbon.2009.03.052

14. Scheuermann, G. M.; Rumi, L.; Steurer, P.; Bannwarth, W.; Mülhaupt, R. J. Am. Chem. Soc. 2009, 131, 8262-8270. doi:10.1021/ja901105a

15. Li, H. B.; Kang, W. J.; Xi, B. J.; Yn, Y.; Bi, H. Y.; Zuhu, Y. C.; Qian, Y. Carbon 2010, 48, 464-469. doi:10.1016/j.carbon.2009.09.063

16. Park, H.; Kim, J.-S.; Choi, B. G.; Jo, S. M.; Kim, D. Y.; Hong, W. H.; Jang, S.-Y. Carbon 2010, 48, 1325-1330. doi:10.1016/j.carbon.2009.11.054

17. Ventura, D. N.; Stone, R. A.; Chen, K.-S.; Hariri, H. H.; Riddle, K. A.; Fellers, J.; Yun, C. S.; Strouse, G. F.; Kroto, H. W.; Acquah, S. F. A. Carbon 2010, 48, 987-994. doi:10.1016/j.carbon.2009.11.016

18. Kudo, S.; Maki, T.; Miura, K.; Mae, K. Carbon 2010, 48, 1186-1195. doi:10.1016/j.carbon.2009.11.042

19. Scholz, K.; Scholz, J.; McQuilla, A. J.; Wagner, G.; Klepel, O. Carbon 2010, 48, 1788-1798. doi:10.1016/j.carbon.2010.01.021

20. Kim, Y. H.; Kim, Y.-T.; Kim, S. H.; Lee, D. Carbon 2010, 48, 2072-2084. doi:10.1016/j.carbon.2010.02.018

21. Tzitzios, V.; Georggakilas, V.; Oikonomou, E.; Karakassides, M.; Petridis, D. Carbon 2006, 44, 848-853. doi:10.1016/j.carbon.2005.10.044

22. Jana, A.; Scheer, E.; Polarz, S. Beilstein J. Nanotechnol. 2017, 8, 688-714. doi:10.3762/bjnano.8.74

23. Li, J.; Liu, C.-y. Eur. J. Inorg. Chem. 2010, 1244-1248. doi:10.1002/ejic.200901048

24. Galstyan, V.; Comini, E.; Kohlmanov, I.; Ponzoni, A.; Sberveglieri, V.; Poli, N.; Faglia, G.; Sberveglieri, G. Beilstein J. Nanotechnol. 2016, 7, 1421-1427. doi:10.3762/bjnano.7.133

25. Bui, M.-P. N.; Lee, S.; Han, K. N.; Pham, X.-H.; Li, C. A.; Choo, J.; Seong, G. H. Chem. Commun. 2009, 5549-5551. doi:10.1039/b906939a

26. Li, W.; Waje, M.; Chen, Z.; Larsen, P.; Yan, Y. Carbon 2010, 48, 995-1003. doi:10.1016/j.carbon.2009.11.017

27. Lee, G.; Shim, J. H.; Kang, H.; Nam, K. M.; Song, H.; Park, J. T. Chem. Commun. 2009, 5036-5038. doi:10.1039/b911068b

28. Seger, B.; Kamat, P. V. J. Phys. Chem. C 2009, 113, 7990-7995. doi:10.1021/jp900360k

29. Dong, L.; Gari, R. R. S.; Li, Z.; Craig, M. M.; Hou, S. Carbon 2010, 48, 781-787. doi:10.1016/j.carbon.2009.10.027

30. Karimi, B.; Kabiri, E. F. Chem. Commun. 2009, 5555-5557. doi:10.1039/b908964k

31. Sun, M.; Zhang, J.; Zhang, Q.; Wang, Y.; Wan, H. Chem. Commun. 2009, 5174-5176. doi:10.1039/b910317a

32. Armelao, L.; Dell'Amico, D. B.; Braglia, R.; Calderazzo, F.; Garbassi, F.; Marra, G.; Mergio, A. Dalton Trans. 2009, 5559-5566. doi:10.1039/b903655e

33. Lightcap, I. V.; Kosel, T. H.; Kamat, P. V. Nano Lett. 2010, 10, 577-583. doi:10.1021/n19035109

34. Dupont, J.; Scholten, J. D. Chem. Soc. Rev. 2010, 39, 1780-1804. doi:10.1039/b822551f 
35. Dupont, J. J. Braz. Chem. Soc. 2004, 15, 341-350. doi:10.1590/S0103-50532004000300002

36. Consorti, C. S.; Suarez, P. A. Z.; de Souza, R. F.; Burrow, R. A.; Farrar, D. H.; Lough, A. J.; Loh, W.; da Silva, L. H. M.; Dupont, J. J. Phys. Chem. B 2005, 109, 4341-4349. doi:10.1021/jp0452709

37. Wasserscheid, P.; Keim, W. Angew. Chem., Int. Ed. 2000, 39, 3772-3789. doi:10.1002/1521-3773(20001103)39:21<3772::AID-ANIE3772>3.0.C $0 ; 2-5$

38. Kim, M. R.; Xu, Z.; Chen, G.; Ma, D. Chem. - Eur. J. 2014, 20, 11256-11275. doi:10.1002/chem.201402277

39. Zan, X.; Bai, H.; Wang, C.; Zhao, F.; Duan, H. Chem. - Eur. J. 2016, 22, 5204-5210. doi:10.1002/chem.201504454

40. Lara, P.; Rivada-Wheelaghan, O.; Conejero, S.; Poteau, R.; Philippot, K.; Chaudret, B. Angew. Chem., Int. Ed. 2011, 50, 12080-12084. doi:10.1002/anie.201106348

41. Golindano, T. C.; Martínez, S. I.; Delgado, O. Z.; Rivas, G. P. Synthesis of Nickel Nanoparticles by Reduction of a Organometallic Precursor with Hydrogen. Technical Proceedings of the 2005 NSTI Nanotechnology Conference and Trade Show; 2005; Vol. 2, pp 634-637. http://www.nsti.org/procs/Nanotech2005v2/10/T73.01

42. Cordente, N.; Amiens, C.; Chaudret, B.; Respaud, M.; Senocq, F.; Casanove, M.-J. J. Appl. Phys. 2003, 94, 6358-6365. doi:10.1063/1.1621081

43. Li, Y.; Liu, J.; Wang, Y.; Wang, Z. L. Chem. Mater. 2001, 13, 1008-1014. doi:10.1021/cm000787s

44. Cormary, B.; Dumestre, F.; Liakakos, N.; Soulantica, K.; Chaudret, B. Dalton Trans. 2013, 42, 12546-12553. doi:10.1039/c3dt50870f

45. Kovalenko, M. V.; Coperet, C. Dalton Trans. 2013, 42, 12520. doi:10.1039/c3dt90116e

46. Metin, Ö.; Sun, X.; Sun, S. Nanoscale 2013, 5, 910-912. doi:10.1039/C2NR33637E

47. Kumara, C.; Dass, A. Nanoscale 2012, 4, 4084-4086. doi:10.1039/c2nr11781a

48. Zhang, Z.-C.; Hui, J.-F.; Guo, Z.-G.; Yu, Q.-Y.; Xu, B.; Zhang, X.; Liu, Z.-C.; Xu, C.-M.; Gao, J.-S.; Wang, X. Nanoscale 2012, 4 , 2633-2639. doi:10.1039/c2nr12135b

49. Kumara, C.; Dass, A. Nanoscale 2011, 3, 3064-3067. doi:10.1039/c1nr10429b

50. Marcos Esteban, R.; Schütte, K.; Marquardt, D.; Barthel, J.; Beckert, F.; Mülhaupt, R.; Janiak, C. Nano-Struct. Nano-Objects 2015, 2, 28-34. doi:10.1016/j.nanoso.2015.07.002

51. Rao, C. N. R.; Vivekchand, S. R. C.; Biswas, K.; Govindaraj, A. Dalton Trans. 2007, 3728-3749. doi:10.1039/b708342d

52. Rao, C. N. R.; Ramakrishna Matte, H. S. S.; Voggu, R.; Govindaraj, A Dalton Trans. 2012, 41, 5089-5120. doi:10.1039/c2dt12266a

53. Taubert, A. Acta Chim. Slov. 2005, 52, 168-170.

54. Waltz, F.; Swider, A. M.; Hoyer, P.; Hassel, T.; Erne, M.; Möhwald, K.; Adlung, M.; Feldhoff, A.; Wickleder, C.; Bach, F.-W.; Behrens, P. J. Mater. Sci. 2012, 47, 176-183. doi:10.1007/s10853-011-5785-0

55. Kemnitz, E. Catal. Sci. Technol. 2015, 5, 786-806. doi:10.1039/C4CY01397B

56. Coman, S. M.; Verziu, M.; Tirsoaga, A.; Jurca, B.; Teodorescu, C.; Kuncser, V.; Parvulescu, V. I.; Scholz, G.; Kemnitz, E. ACS Catal. 2015, 5, 3013-3026. doi:10.1021/acscatal.5b00282

57. Antipov, E. V.; Khasanova, N. R.; Fedotov, S. S. IUCrJ 2015, 2, 85-94. doi:10.1107/S205225251402329X

58. Poizot, P.; Laruelle, S.; Grugeon, S.; Dupont, L.; Tarascon, J.-M. Nature 2000, 407, 496-499. doi:10.1038/35035045
59. Yamakawa, N.; Jiang, M.; Key, B.; Grey, C. P. J. Am. Chem. Soc. 2009, 131, 10525-10536. doi:10.1021/ja902639w

60. Tarascon, J.-M.; Armand, M. Nature 2001, 414, 359-367. doi:10.1038/35104644

61. Breitung, B.; Reddy, M. A.; Chakravadhanula, V. S. K.; Engel, M.; Kübel, C.; Powell, A. K.; Hahn, H.; Fichtner, M. Beilstein J. Nanotechnol. 2013, 4, 705-713. doi:10.3762/bjnano.4.80

62. Beckert, F.; Friedrich, C.; Thomann, R.; Mülhaupt, R. Macromolecules 2012, 45, 7083-7090. doi:10.1021/ma301379z

63. Schütte, K.; Barthel, J.; Endres, M.; Siebels, M.; Smarsly, B. M.; Yue, J.; Janiak, C. ChemistryOpen 2017, 6, 137-148. doi:10.1002/open.201600105

64. Rutz, C.; Schmolke, L.; Gvilava, V.; Janiak, C. Z. Anorg. Allg. Chem. 2017, 643, 130-135. doi:10.1002/zaac.201600437

65. Archer, D. G.; Widegren, J. A.; Kirklin, D. R.; Magee, J. W. J. Chem. Eng. Data 2005, 50, 1484. doi:10.1021/je050136i

66. Olchowka, J.; Suta, M.; Wickleder, C. Chem. - Eur. J. 2017, 23, 12092-12095. doi:10.1002/chem.201702375

67. Lorbeer, C.; Behrends, F.; Cybinska, J.; Eckert, H.; Mudring, A.-V. J. Mater. Chem. C 2014, 2, 9439-9450. doi:10.1039/C4TC01214C

68. Göbel, R.; Xie, Z.-L.; Neumann, M.; Günter, C.; Löbbicke, R.; Kubo, S.; Titirici, M.-M.; Giordano, C.; Taubert, A. CrystEngComm 2012, 14, 4946-4951. doi:10.1039/c2ce25064k

69. Taubert, A. Angew. Chem., Int. Ed. 2004, 43, 5380-5382. doi:10.1002/anie.200460846

70. Cibin, G.; Mottana, A.; Marcelli, A.; Brigatti, M. F. Mineral. Petrol. 2005, 85, 67-87. doi:10.1007/s00710-005-0099-z

71. Burns, P. C.; Novak, M.; Hawthorne, F. C. Can. Mineral. 1995, 33, 1205-1213.

72. Enami, M.; Suzuki, K.; Liou, J. G.; Bird, D. K. Eur. J. Mineral. 1993, 5, 219-231. doi:10.1127/ejm/5/2/0219

73. Robert, J.-L.; Beny, J.-M.; Della, V. G.; Hardy, M. Eur. J. Mineral. 1993, 5, 7-18. doi:10.1127/ejm/5/1/0007

74. Abercrombie, H. J.; Skippen, G. B.; Marshall, D. D. Contrib. Mineral. Petrol. 1987, 97, 305-312. doi:10.1007/BF00371994

75. Robert, J.-L.; Della, V. G.; Thauvin, J.-L. Eur. J. Mineral. 1989, 1, 203-211. doi:10.1127/ejm/1/2/0203

76. Schütte, K. Synthese und Untersuchung von mono- und bimetallischen Nanopartikeln, Immobilisierung auf funktionasisierten Graphenoberflächen und Katalyse. Ph.D. Thesis, Heinrich-Heine-Universität, Düsseldorf, Germany, 2015.

77. Thermo Scientific XPS: Knowledge Base. http://xpssimplified.com/periodictable.php (accessed Jan 15, 2017).

78. Moulder, J. F.; Stickle, W. F.; Sobol, P. E.; Bomben, K. D. Handbook of X-ray Photoelectron Spectroscopy; Perkin-Elmer Corporation: Eden-Prairie, MN, U.S.A., 1992.

79. Goncalves, G.; Marques, P. A. A. P.; Granadeiro, C. M.; Nogueira, H. I. S.; Singh, M. K.; Grácio, J. Chem. Mater. 2009, 21, 4796-4802. doi:10.1021/cm901052s

80. Pham, C. V.; Eck, M.; Krueger, M. Chem. Eng. J. 2013, 231, 146-154. doi:10.1016/j.cej.2013.07.007

81. Borchard-Tuch, C. Chem. Unserer Zeit 2003, 37, 436-437. doi:10.1002/ciuz.200390091

82. Di Carlo, L.; Conte, D. E.; Kemnitz, E.; Pinna, N. Chem. Commun. 2014, 50, 460-462. doi:10.1039/c3cc47413e

83. Li, C.; Gu, L.; Tsukimoto, S.; van Aken, P. A.; Maier, J. Adv. Mater. 2010, 22, 3650-3654. doi:10.1002/adma.201000535

84. Li, C.; Gu, L.; Tong, J.; Maier, J. ACS Nano 2011, 5, 2930-2938. doi:10.1021/nn1035608 
85. Badway, F.; Cosandey, F.; Pereira, N.; Amatucci, G. G. J. Electrochem. Soc. 2003, 150, A1318-A1327. doi:10.1149/1.1602454

86. Zhou, J.; Zhang, D.; Zhang, X.; Song, H.; Chen, X. ACS Appl. Mater. Interfaces 2014, 6, 21223-21229. doi:10.1021/am506236n

87. Reddy, M. A.; Breitung, B.; Chakravadhanula, V. S. K.; Wall, C.; Engel, M.; Kübel, C.; Powell, A. K.; Hahn, H.; Fichtner, M. Adv. Energy Mater. 2013, 3, 308-313. doi:10.1002/aenm.201200788

88. Wang, F.; Robert, R.; Chernova, N. A.; Pereira, N.; Omenya, F.; Badway, F.; Hua, X.; Ruotolo, M.; Zhang, R.; Wu, L.; Volkov, V.; Su, D.; Key, B.; Whittingham, M. S.; Grey, C. P.; Amatucci, G. G.; Zhu, Y.; Graetz, J. J. Am. Chem. Soc. 2011, 133, 18828-18836. doi:10.1021/ja206268a

89. Wang, F.; Kim, S.-W.; Seo, D.-H.; Kang, K.; Wang, L.; Su, D.; Vajo, J. J.; Wang, J.; Graetz, J. Nat. Commun. 2015, 6, 6668. doi:10.1038/ncomms7668

90. Balaya, P.; Li, H.; Kienle, L.; Maier, J. Adv. Funct. Mater. 2003, 13, 621-625. doi:10.1002/adfm.200304406

91. Li, L.; Jacobs, R.; Gao, P.; Gan, L.; Wang, F.; Morgan, D.; Jin, S. J. Am. Chem. Soc. 2016, 138, 2838-2848. doi:10.1021/jacs.6b00061

92. Bilecka, I.; Niederberger, M. Nanoscale 2010, 2, 1358-1374. doi:10.1039/b9nr00377k

93. Chen, W.; Gutmann, B.; Kappe, C. O. ChemistryOpen 2012, 1, 39-48. doi:10.1002/open.201100013

94. Rodríguez, A. M.; Prieto, P.; de la Hoz, A.; Díaz-Ortiz, A.; Martin, R.; Garcia, J. I. ChemistryOpen 2015, 4, 308-317. doi:10.1002/open.201402123

95. Lim, B. S.; Rahtu, A.; Park, J.-S.; Gordon, R. G. Inorg. Chem. 2003, 42, 7951-7958. doi:10.1021/ic0345424

96. Schmidt, S.; Schulz, S.; Bläser, D.; Boese, R.; Bolte, M. Organometallics 2010, 29, 6097-6103. doi:10.1021/om1008549

97. Makinson, J. D.; Lee, J. S.; Magner, S. H.; De Angelis, R. J.; Weins, W. N.; Hieronymus, A. S. Adv. X-Ray Anal. 2000, 42, 407.

98. Zhang, F.; Chan, S.-W.; Spanier, J. E.; Apak, E.; Jin, Q.; Robinson, R. D.; Herman, I. P. Appl. Phys. Lett. 2002, 80, 127-129. doi:10.1063/1.1430502

99. Reddy, K. M.; Manorama, S. V.; Reddy, A. R. Mater. Chem. Phys. 2003, 78, 239. doi:10.1016/S0254-0584(02)00343-7

100. Kurian, M.; Kunjachan, C. Nano-Struct. Nano-Objects 2015, 1, 15-23. doi:10.1016/j.nanoso.2015.06.002

101.Manhas, M.; Kumar, V.; Sharma, V.; Ntwaeaborwa, O. M.; Swart, H. C. Nano-Struct. Nano-Objects 2015, 3, 9-16. doi:10.1016/j.nanoso.2015.06.003

102. Ernst Ruska-Centre for Microscopy and Spectroscopy with Electrons. J. Large-Scale Res. Facil. 2016, 2, A77. doi:10.17815/jlsrf-2-138

103. Ernst Ruska-Centre for Microscopy and Spectroscopy with Electrons. J. Large-Scale Res. Facil. 2016, 2, A41. doi:10.17815/jlsrf-2-66

\section{License and Terms}

This is an Open Access article under the terms of the Creative Commons Attribution License

(http://creativecommons.org/licenses/by/4.0), which permits unrestricted use, distribution, and reproduction in any medium, provided the original work is properly cited.

The license is subject to the Beilstein Journal of Nanotechnology terms and conditions: (http://www.beilstein-journals.org/bjnano)

The definitive version of this article is the electronic one which can be found at:

doi:10.3762/bjnano.8.247 